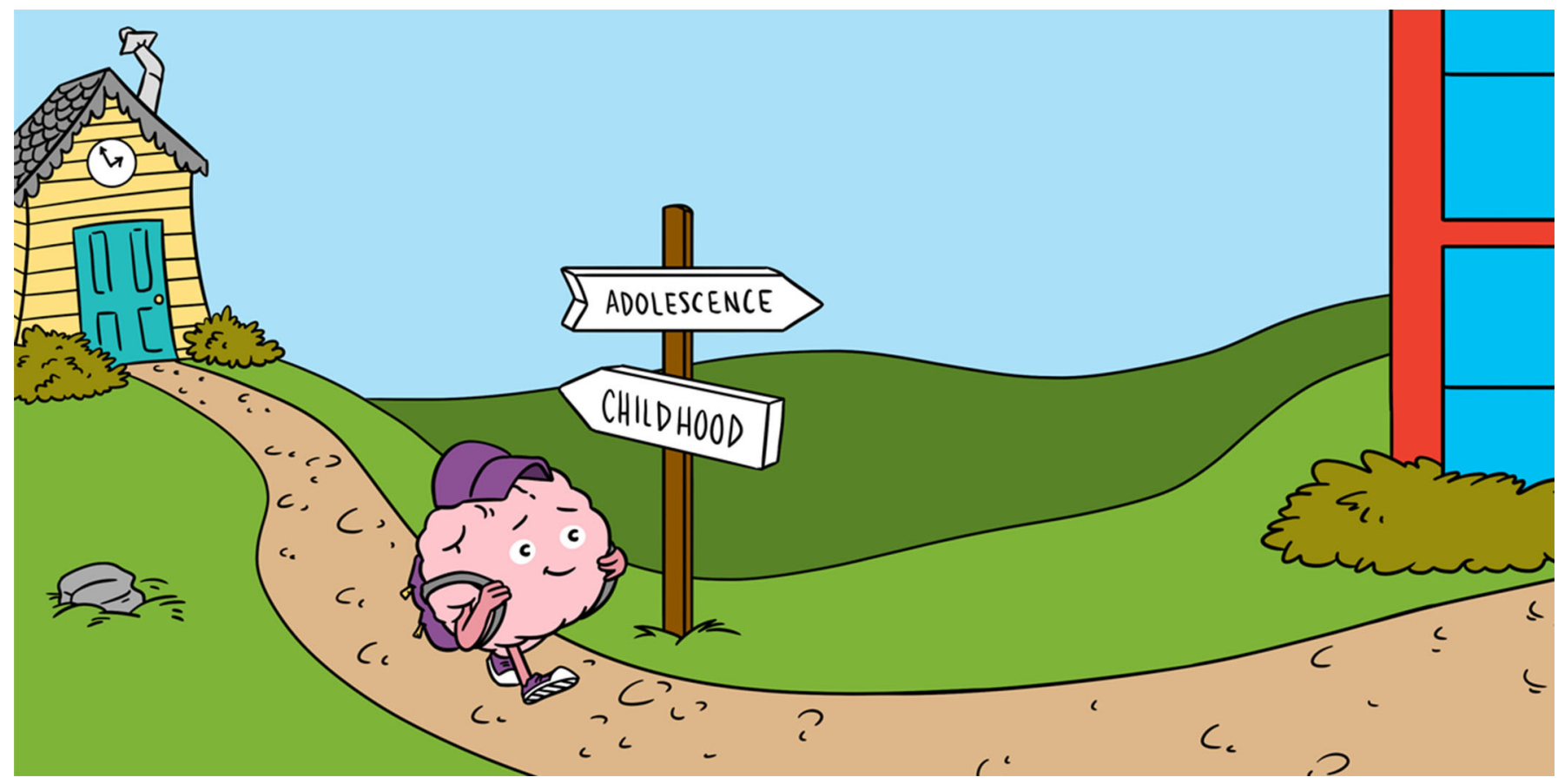

\title{
THE ADOLESCENT BRAIN IS LITERALLY AWESOME
}

\section{Kathryn L. Mills ${ }^{1,2^{*}}$ and Jeya Anandakumar ${ }^{1,3}$}

${ }^{1}$ Developing Brains in Context Lab, Department of Psychology, Center for Translational NeuroScience, University of Oregon, Eugene, OR, United States

${ }^{2}$ PROMENTA Research Center, Department of Psychology, University of Oslo, Oslo, Norway

${ }^{3}$ Portland State University, Portland, OR, United States

YOUNG REVIEWERS:

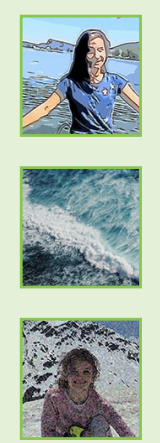

ISABELLA

AGE: 13

ALINE

AGE: 13

MARILIA

AGE: 13
The human brain undergoes a long period of development. While the brain is changing dramatically in childhood, there are also changes during the second decade of life that make this period, known as adolescence, awesome. Adolescents have brains more capable of change than adults and, unlike children, adolescents have a greater ability to actually shape the brain's development. Heightened information processing abilities and social sensitivity during adolescence also make this a time of increased ability to navigate our complex social world. This article discusses how current research on brain development can be used to empower adolescents as capable learners of the world around them. We make recommendations on how educational settings can nurture brain development and optimize the learning environment during adolescence. 


\section{AWESOME}

Inspiring great admiration, apprehension, or fear.

\section{MAGNETIC}

RESONANCE

\section{IMAGING}

A way to scans the body to take pictures of its inside, like the brain.

\section{CEREBRUM}

The front part of the brain, which is involved with thought, decision, emotion, and character.

\section{NEURON}

A nerve cell.

\section{CORTEX}

The outer layer of the cerebrum, composed of folded gray matter.

\section{AXON}

A long thin part of a neuron that sends the signal from one end of the neuron to the other end.

\section{INTRODUCTION}

The adolescent brain is awesome, and here we explain why. Adolescence is the period of life that often begins with changes in the body related to puberty. But the brain is also changing during this time, and continues to change even after we finish puberty-well into our twenties [1]! The changes in the brain are reflected in the changes in behavior that we can often see during adolescence, such as the desire to explore, form new relationships, and navigate our changing social world.

\section{BRAIN STRUCTURE CHANGES DURING ADOLESCENCE}

Researchers use a technique called magnetic resonance imaging (MRI), which uses magnets and radio waves, to take photos of the brain while a person is lying inside what looks like a giant donut (Figure 1). MRI studies can show us how the human brain changes in its structure (anatomy) and organization (how it is linked up) across adolescence.

The brain is composed of many parts, but here we focus on the tissues of the cerebrum, which is the largest part of the brain (Figure 2A). The cerebrum is made of two kinds of tissue, called gray matter and white matter. The gray matter, which is made of brain cells called neurons and their connections, can be found on the outside of the cerebrum (called the cortex), as well as deep inside the cerebrum. Gray matter contains most of the neuronal cell bodies and makes up regions of the brain that are essential for muscle control, sensory perception, decision making, and self-control. Gray matter decreases during adolescence, by about $1.5 \%$ a year ([1]; Figure 2B). However, this decrease is not a bad thing! The decrease in gray matter is thought to be related to the fine-tuning of connections between brain cells, and also related to the increase in the other tissue in the cerebrum: the white matter.

The white matter of the cerebrum is found under the cortex, and is made of long fibers of neurons, called axons, that send the signals that connect together different parts of the brain. White matter increases in early adolescence but seems to be stable by the mid-teens (Figure 2C). The increase in white matter is thought to be related an increase in the speed of signals sent between brain cells. Anatomical illustrations of gray and white matter are shown in Figure 3.

\section{HOW DOES BRAIN ORGANIZATION CHANGE DURING ADOLESCENCE?}

Researchers can also use MRI to see how the brain is organized, in terms of how different parts of the brain are connected. Because the 
Figure 1

(A) A magnetic resonance imaging (MRI) machine looks like (B) a donut.

\section{Figure 2}

(A) An image of a section of a human's cerebrum, obtained using MRI. The view is as if you were looking from the top of the head down into the brain. The gray squiggles that curve around the white areas are gray matter of the cortex, and the white areas are the white matter. (B) The amount of gray matter in the cortex decreases during adolescence. (C) The amount of white matter in the cerebrum increases during adolescence. In both B and $C$, each dot on the graph represents the brain measure of one individual at one time, as acquired with MRI. Dots are connected to show the measurements gathered from one individual. Data was collected in four different research labs, and the average of the data at each site is shown with the four bold lines (figure adapted from Tamnes et al. [2] and Mills et al. [1]).

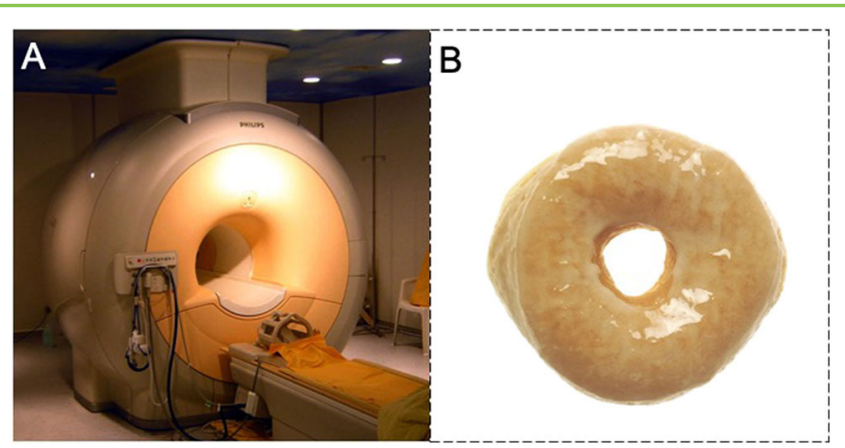

Figure 1

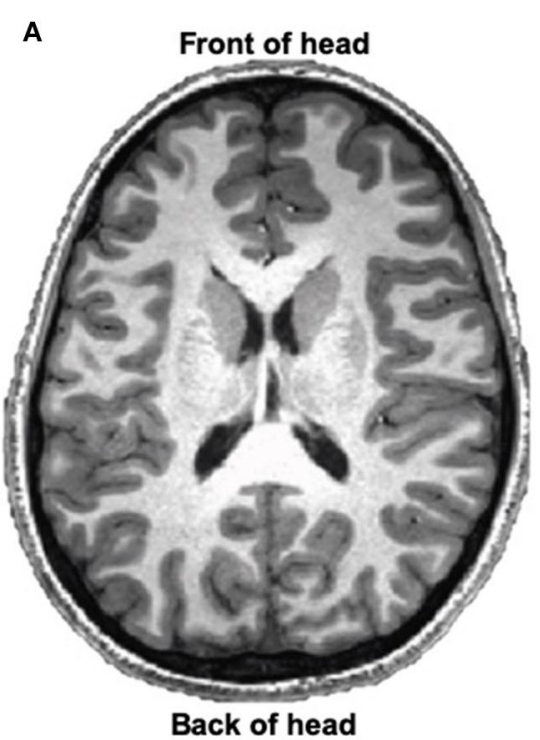

B
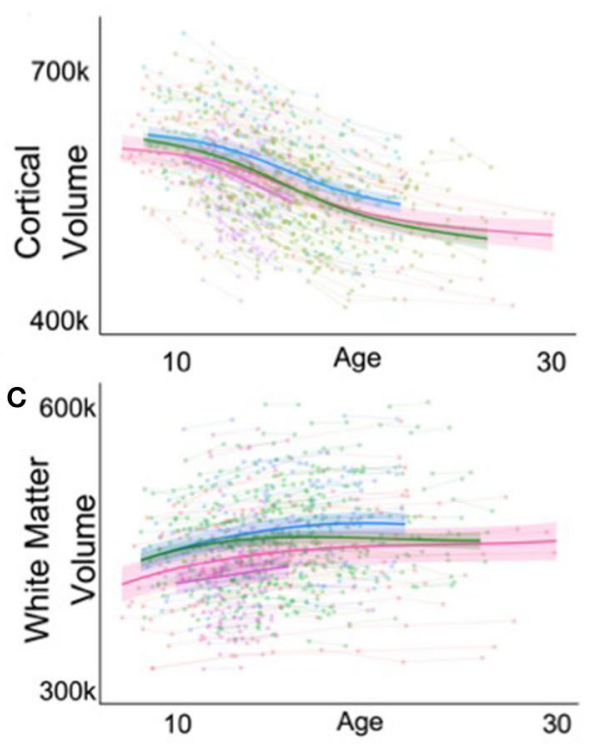

Figure 2

brain is changing so much in adolescence, its organization can be influenced by what we do, our experiences, and the environments we live in. The brain is a large network-different regions of the brain communicate with each other as a person performs different functions or behaviors, such as thinking about other people or moving around in the world. These brain communication patterns can be studied using a slightly different technique, called functional MRI (fMRI). This technique examines the amount of oxygen in the blood flowing throughout the brain as a measure of brain activity. When different regions of the brain show similar patterns of brain activity, they are said to be functionally connected.

Typical behaviors that we see during adolescence, such as thinking about other people and making decisions, have been seen to relate to certain patterns of brain activity between functionally connected regions in the brain. Not every adolescent has the same brain organization, and not every adolescent engages in typical adolescent behaviors. The way individuals differ in their patterns of brain activity can relate to differences in behavior. 
Figure 3

A silhouette of a girl with an image of the human brain overlaid to illustrate another view of the human brain. In the middle is a drawing of a cross-section of the human brain, showing the white matter underneath the cortex. The white matter tracts make up the white matter, with one set of white matter tracts (called the corona radiata) illustrated. A drawing of the cortical column of a developing human is illustrated in the yellow box. This drawing shows how neurons are arranged in the cortex, but cortical gray matter volume also includes many cellular components not seen here, including glial cells and blood vessels. These drawings were obtained from two repositories of free-use images: WikiMedia Commons and Pixabay.

\section{TEMPORAL}

\section{DISCOUNTING} PREFERENCE

An individual's preference for whether they would choose a smaller sooner reward or be willing to wait for a larger later reward.

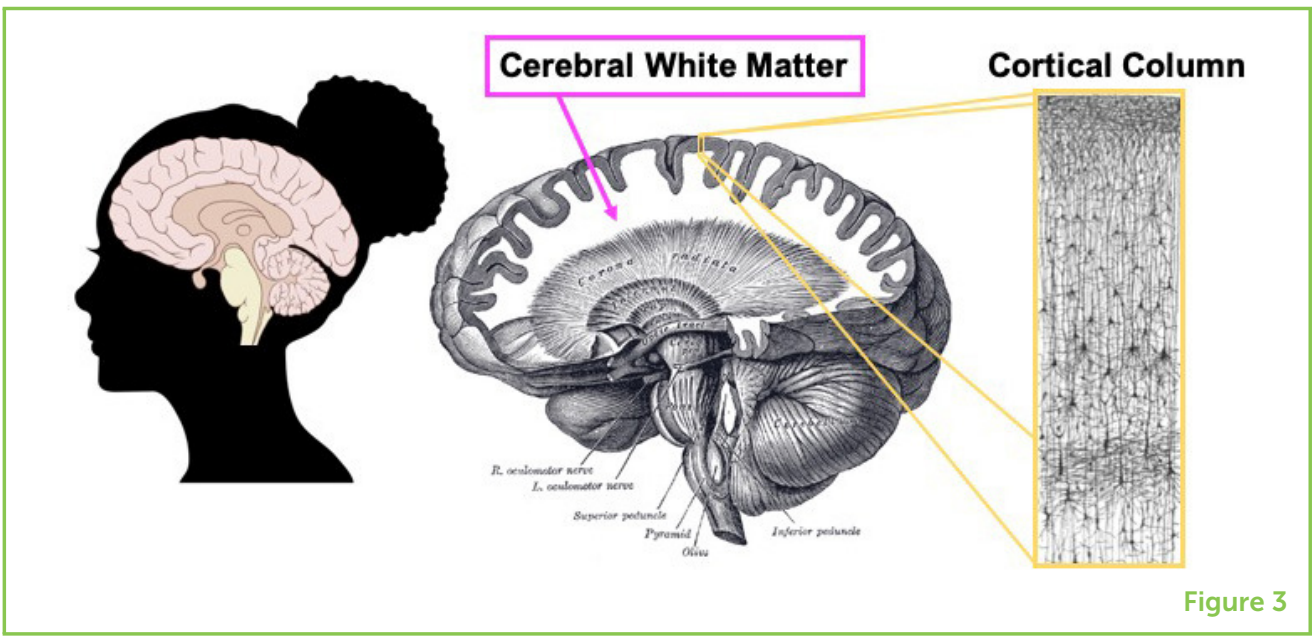

One example of a behavior that changes during adolescence is called temporal discounting preference. This behavior has to do with how long we are willing to wait for rewards, particularly whether an individual will choose a smaller reward that is available immediately, or a larger reward that he or she must wait for. We studied how this preference changes in the transition into adolescence. We found that patterns of brain activity that link together regions of the brain involved in controlling our behavior to regions of the brain involved in valuing things in the world related to an individual's temporal discounting preference [3]. While there might be the stereotype that adolescents, in general, do not have the patience to wait for a larger reward when a smaller reward is immediately available, our study found that individuals differ in their behavior, and this difference is related to an individual's brain organization.

Brain imaging studies have shown that the brain reorganizes in adolescence. Because our brains are changing so much, our experiences in adolescence can help shape the brain's organization. By engaging in certain patterns of behavior, we are making certain patterns of brain activity stronger. This makes leaps in intellectual and emotional development possible during adolescence.

\section{WHY THE CHANGING ADOLESCENT BRAIN REPRESENTS A UNIQUE OPPORTUNITY}

Changes in the brain's structure and organization during adolescence are greater than what we see in adulthood, but less than what we see during infancy and childhood. But, unlike childhood, adolescence is a time when we have a greater ability to actually shape how our own brains are developing. This is because we can understand more about ourselves and the world, we are more motivated and engaged, and we have an increased ability to make choices that can impact the changing brain. This is what makes the adolescent brain awesome. 
Some of the brain's abilities that increase during adolescence include abstract thinking, considering many points of view, and being able to think about the process of thinking. Some research suggests that adolescents even have a greater capability than adults and children to solve problems in new and creative ways due to their ability to think about different concepts at the same time [4]. The brain's abilities that are already present during adolescence can be used to encourage further healthy brain growth, but this requires giving adolescents the freedom to make their own choices. For example, encouraging adolescents to set their own goals will encourage the brain activity involved in forming self-identity and considering long-term consequences. Adolescents are often quite concerned about how they are perceived by their peers. While this aspect of social sensitivity is often talked about as a negative aspect of adolescent behavior, it can actually be a positive when the social environment is healthy [5]. Another example of social sensitivity that increases during adolescence is concern with larger social structures and world events [6]. Adults, who often have a greater ability to change the social environment than adolescents, should work toward giving adolescents more opportunities for positive brain growth.

\section{WHAT CAN YOUR TEACHERS DO TO OPTIMIZE THE LEARNING ENVIRONMENT OF ADOLESCENT STUDENTS?}

Because the brain can be so easily shaped during adolescence, it is important for teachers and parents to nurture the developing brain. Optimizing the school learning environment is one of the most effective ways to support adolescents. What we know about the developing brain is that, compared with younger children, adolescents have a greater ability to understand more complex topics. Understanding what is happening in their own brains can help adolescents impact their own development. One way this can be done is through integrating developmental topics, such as decision-making, drug addiction, conflict resolution, and educational planning in the school curriculum. Here are some other ways to optimize the school learning environment. Consider sharing them with your teachers!

\section{MAKE LEARNING COLLABORATIVE AND DIVERSE}

Rather than ignore the motivation to socialize during adolescence, teachers can utilize this social motivation by encouraging group discussions and engagement among students. Asking for student advice and feedback on classroom activities can help students feel interested and more involved in the learning environment. Including students from different grades could help students learn new skills and see the project from different perspectives as students from different age groups can contribute different skills to a discussion or project. 


\section{CHANGE CLASSROOM ENVIRONMENT}

Think about your classroom. How are the tables and chair arranged? Are they in straight long rows or are they in small circles? It might feel socially isolating to sit in long rows and only be able to see classmates from the back or side. This type of arrangement of the desks and/or the chairs can be changed to welcome collaboration and learning. Consider asking your teacher if they are open to experimenting with trying new arrangements like small circles. In addition to respecting the inherent social motivation of adolescence, rearrangement of classroom furniture can help with social anxiety, because it might be easier to reach out and talk to other students in the group.

\section{FOSTER INDEPENDENCE}

Teachers can foster independence in the classroom by allowing students to lead the way. This could include allowing students to come up with a part of the syllabus or the guidelines for a project. Allowing students to explore what they are interested in will drive learning. When students are able to create their own guidelines and overcome difficulties through hard work and collaboration, they will be more prepared to take on new challenges and thrive in difficult situations.

\section{INTERACT WITH THE COMMUNITY}

The typical classroom environment might be too artificial and structured. Students should be encouraged to collaborate with the world outside of the classroom. Community-based field trips might help students to apply things they have learned in class to the real world. This complements the increased sensitivity to one's own social world that happens during adolescence.

\section{WHAT DOES THIS MEAN FOR YOU?}

Adolescence is a period of rapid growth, development, and learning. This presents a unique opportunity for adolescents to have a greater ability to actually shape the brain's development. We can make certain patterns of our brain activity stronger by engaging in certain types of behaviors. One of the ways you can engage in your own development is by learning and understanding what is happening in your own brain. Awesome, right?

\section{AUTHOR CONTRIBUTIONS}

KM outlined the paper. KM and JA wrote the paper. 


\section{ACKNOWLEDGMENTS}

We would like to thank the reviewers and editors of this article for their helpful comments and suggestions. KM would like to thank Celilo Mitchell and Jerome Mitchell for inspiration. We would also like to thank those who assisted in the translation of the articles in this Collection to make them more accessible to kids outside English-speaking countries, and for the Jacobs Foundation for providing the funds necessary to translate the articles. For this article, we would especially like to thank Nienke van Atteveldt and Sabine Peters for the Dutch translation.

\section{REFERENCES}

1. Mills, K. L., Goddings, A. L., Herting, M. M., Meuwese, R., Blakemore, S. J., Crone, E. A., et al. 2016. Structural brain development between childhood and adulthood: convergence across four longitudinal samples. Neuroimage 141:273-81. doi: 10.1016/j.neuroimage.2016.07.044

2. Tamnes, C. K., Herting, M. M., Goddings, A. L., Meuwese, R., Blakemore, S. J., Dahl, R. E., et al. 2017. Development of the cerebral cortex across adolescence: a multisample study of inter-related longitudinal changes in cortical volume, surface area, and thickness. J. Neurosci. 37, 3402-12.

3. Anandakumar, J., Mills, K. L., Earl, E. A., Irwin, L., Miranda-Dominguez, O., Demeter, D. V., et al. 2018. Individual differences in functional brain connectivity predict temporal discounting preference in the transition to adolescence. Dev. Cogn. Neurosci. 34:101-13. doi: 10.1016/j.den.2018.07.003

4. Stevenson, C. E., Kleibeuker, S. W., de Dreu, C. K. W., and Crone, E. A. 2014. Training creative cognition: adolescence as a flexible period for improving creativity. Front. Hum. Neurosci. 8:827. doi: 10.3389/fnhum.2014.00827

5. Telzer, E. H. 2016. Dopaminergic reward sensitivity can promote adolescent health: a new perspective on the mechanism of ventral striatum activation. Dev. Cogn. Neurosci. 17:57-67. doi: 10.1016/j.dcn.2015.10.010

6. Sherrod, L. 2007. "Civic engagement as an expression of positive youth development," in Approaches to Positive Youth Development, eds R. K. Silbereisen and R. M. Lerner (London: SAGE Publications Ltd), 59-74. doi: $10.4135 / 9781446213803$

SUBMITTED: 30 September 2019; ACCEPTED: 15 May 2020; PUBLISHED ONLINE: 25 June 2020.

EDITED BY: Sabine Peters, Leiden University, Netherlands

CITATION: Mills KL and Anandakumar J (2020) The Adolescent Brain Is Literally Awesome. Front. Young Minds 8:75. doi: 10.3389/frym.2020.00075

CONFLICT OF INTEREST: The authors declare that the research was conducted in the absence of any commercial or financial relationships that could be construed as a potential conflict of interest. 

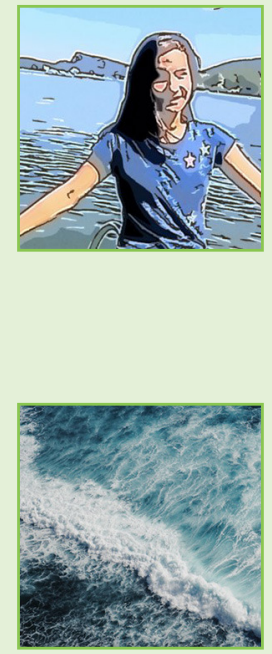

COPYRIGHT (c) 2020 Mills and Anandakumar. This is an open-access article distributed under the terms of the Creative Commons Attribution License (CC BY). The use, distribution or reproduction in other forums is permitted, provided the original author(s) and the copyright owner(s) are credited and that the original publication in this journal is cited, in accordance with accepted academic practice. No use, distribution or reproduction is permitted which does not comply with these terms.

\section{YOUNG REVIEWERS}

\section{ISABELLA, AGE: 13}

My name is Isabella and I am 13 years old. I was born in New York and I live in Switzerland. I love art, reading books, singing, dancing, and playing the piano. My favorite sport is swimming. I also have great interest in math, nature, and science, especially everything about space, time, and matter. In the future, I would like to be an aeronautic engineer or an architect. I am always very curious to learn more about the world around us.

\section{ALINE, AGE: 13}

My name is Aline, I am 13 years old. My favorite hobbies include theater, playing the clarinet, drawing, and reading. I am fascinated with Greek mythology; my favorite books include the Harry Potter and the Percy Jackson series. At school, I really enjoy Maths and Science.

\section{MARILIA, AGE: 13}

Hallo! My name is Marilia. I am 13 years old and I like ice skating, rythmic gymnastics, and playing football. I have a small dog which I love! One day I would like to travel to Australia and see the coalas. I enjoy to be with my friends and go swimming or watch a film with them.

\section{AUTHORS}
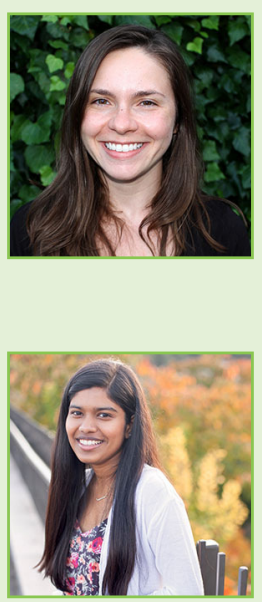

\section{KATHRYN L. MILLS}

Kate Mills is an Assistant Professor in the Department of Psychology at the University of Oregon. She studies how the brain changes from childhood to adulthood, and how we develop the strategies to thrive in our specific environment. She spends all of her free time with her family, exploring and enjoying the beautiful places around her home in Eugene, Oregon *klmills@uoregon.edu.

\section{JEYA ANANDAKUMAR}

Jeya Anandakumar is an undergraduate student at Portland State University in Portland, Oregon. She is majoring in biology and minoring in chemistry with a focus on neuroscience. Her research interests include developmental neuroscience and neurogenetics. She was previously a young reviewer for Frontiers for Young Minds. In her free time, she enjoys playing the flute and taking dance classes. 